\title{
Will We Know More or Less about Chemical Risks under REACH?
}

\author{
Martin Scheringer ${ }^{\star a}$, Stefan Böschen ${ }^{\mathrm{b}}$, and Konrad Hungerbühler ${ }^{\mathrm{a}}$
}

\begin{abstract}
After a brief overview of the history of the regulation of chemicals, we summarize problems with the current European chemicals legislation that have led to the development of the new European regulation, REACH (Registration, Evaluation and Authorization of CHemicals). Two key aspects are (i) the problem of the large number of existing chemicals for which a practicable evaluation approach had to be found and (ii) the political intention to employ the precautionary principle as a guiding principle of the new regulation. The precautionary principle is related to the question of how risk assessors can deal with the lack of data, uncertainty, and non-knowledge. A particular aspect of dealing with fundamental uncertainties in chemical risk assessment is the use of hazard indicators, in particular for the properties persistence, bioaccumulation, and toxicity (PBT assessment). We analyze the way in which PBT assessments will have to be carried out under REACH. We estimate how many persistent chemicals might be expected among the existing chemicals and discuss uncertainties that impede the identification of these persistent chemicals. Our interpretation of how hazard assessment approaches are implemented in REACH is that the scientific development of hazard assessment methods has not yet provided the practical tools needed for a more consistent and workable approach to PBT assessment under REACH.
\end{abstract}

Keywords: Chemicals legislation · Hazard assessment · PBT assessment · REACH · Risk assessment

\section{Introduction}

For a long time, the science-based design of the chemical industry used to be a model of the progressive forces of science and technology. New products and production technology should guarantee economic and social welfare. However, from the very beginning the chemical industry has been confronted with requests for risk control. The chemical industry was considered as dangerous. Therefore, in the second half of the 19th century first forms of chemicals regulation emerged. During this pro-

\footnotetext{
${ }^{*}$ Correspondence: Dr. M. Scheringera

Tel.: +4144632 3062

Fax: +41446321189

E-Mail: scheringer@chem.ethz.ch

anstitute for Chemical and Bioengineering

ETH Zurich

Wolfgang-Pauli-Str. 10

$\mathrm{CH}-8093$ Zürich

bWissenschaftszentrum Umwelt

Universität Augsburg

Universitätsstr. $1 a$

D-86159 Augsburg
}

cess some basic assumptions were established. A first assumption was that risks of chemicals need to be evaluated using sound knowledge based on empirical evidence. Until the 1990s, chemicals regulation was based on the assumption that this kind of knowledge was available or could be generated. However, this strategy turned out to be problematic because it was not possible to evaluate the great number of existing chemicals (about 100,000) within this conceptual framework. In addition, it was not easily possible to integrate the precautionary principle in the field of chemicals legislation (Section 2). In the light of these difficulties several states within the EU initiated in 1997 a debate about a new chemicals policy. The most advanced chemicals legislation should be developed. The outcome is REACH [1]. New approaches to hazard assessment and a regulation taking into account fundamental uncertainties were included in REACH and even enshrined as guiding principles. At the same time, the intention was to develop a coherent body of chemicals regulation and, in particular, to abandon the distinction between new and existing chemicals. The result can be interpreted - so our first hypothesis - as an integration of the precautionary principle in the field of chemicals policy. We describe this process with regard to the fundamental political and institutional innovations (Section 3). However, the precautionary principle was integrated only to a limited extent. This is shown by an overview of assessment approaches and of the role of indicators for persistence, bioaccumulation and toxicity $(\mathrm{P}, \mathrm{B}$, and $\mathrm{T})$ in different EU documents ranging from the first Technical Guidance Document of 1996 to the most recent draft of the REACH legislation [1-4]. In our argumentation we focus on environmental risk assessment and exposure analysis; we do not deal with human health and the analysis of toxic effects. We put forward the hypothesis that, in the development of REACH, the problem of 'lack of knowledge' was still tackled in the spirit of the search for comprehensive empirical evidence. Therefore, the fundamental problem of non-knowledge, which is associated with the precautionary principle, was not really reflected. An interpretation of the precautionary principle that truly addresses non-knowledge aims to detect hitherto unknown hazards. It comes into work before certain risks can be stated definitely and proven empirically.

For such an approach, procedures working with indicators of possible risk (proxy measures) are necessary. Hazard assessment and, more specifically, PBT assessment stands for an interpretation of the precautionary principle taking into account the problem of non-knowledge (Section 4). We call this a "non-knowledge-ori- 
ented' interpretation of the precautionary principle. Finally, there is the question of why it has not been possible to implement a non-knowledge oriented definition of the precautionary principle in REACH. Our third hypothesis is that the limits of the political implementation of the precautionary principle are caused by limits of scientific methods for hazard assessment. A scientific consensus about the most suitable indicators for the properties $\mathrm{P}, \mathrm{B}$ and $\mathrm{T}$ has not been reached, nor is a set of established and ready-to-use methods for PBT assessments available for registrants of chemicals.

Finally, we ask what can be done to further develop the methods of hazard assessment (Section 5).

\section{Short History of the Regulation of Chemicals}

The regulation of chemicals and chemical processes is as old as the chemical industry itself [5]. There are two main aspects: risks of chemistry and the perception of risks. In the field of chemistry, scientists are willing to take high risks and the public has an ambivalent perception of chemicals and the associated risks. From the very beginning of the chemical industry in the 19 th century, chemists have been aware of the risks, but they have made them a part of their professional ethics. Writer Primo Levi noted in his famous book, The Periodic Table: "In this place, too, nobody wasted many words teaching us how to protect ourselves from acids, caustics, fires, and explosions; it appeared that the Institute's rough and ready morality counted on the process of natural selection to pick out those among us most qualified for physical and professional survival." [6]. Chemists handled hazardous processes or substances and took risks in order to advance scientific and technological knowledge. Simultaneously, the chemical industry had to confront conflicts because negative side-effects occurred, such as exhaust gas pollution or pollution of rivers. Hence, compensations had to be found but they had to be designed in a way that innovative forces were not obstructed. The 'triangle of industry politics'; industry, science and politics, tried to limit controversial debates in the public to a minimum. However, this worked only temporarily because accidents or risk of other technologies stimulated new debates.

\subsection{First Generation: Advancement of Industry and Danger Prevention}

The development of the chemical industry in the second half of the 19th century was very dynamic. On the one hand, the chemical industry came into conflict with established industrial branches, e.g. be- cause of competition for resources; on the other hand there were acute conflicts inside the chemical plants. Workers were exposed to toxic substances and workplace conditions were often bad. Nevertheless, danger prevention was organized in a way that should not hamper the technological and economic progress. First, regulations were established that defined responsibilities in such a way that the public carried the burden of chemical risks [7]. Second, regulations were found that mitigated the conflicts between different users of natural resources [8]. Third, industry developed technical solutions, e.g. in the form of washers or higher smokestacks. Fourthly, among industry, occupational hygiene, and politics an efficient system was established to analyze, monitor and mitigate occupational health problems and environmental hazards. The basso continuo of this evolution was an occupational medicine which focused more on the 'resistance against toxics' of workers than on toxics-free workplace conditions. All these strategies and institutional regimes were correlated with the societal consensus that 'belching smokestacks' heralded the scientific-technological progress but not hazards. This model remained unquestioned until the late 1950s.

\subsection{Second Generation: Risks and Chances}

In the 1960 s the direction of the discourse changed and during the next twenty years a new regime of regulation of hazardous chemicals emerged [9]. First, chemical industry, e.g. in the DDT debate, made headlines in the political debate. Thereby, the precautionary principle received increasing public attention and gained political relevance $[10$, p. 2]. Second, the types of risks changed. New classes of substances and increasing production volumes defined a new context. In the public perception the 'production of risks' became as relevant as the 'production of chemicals'. Third, a new field of research developed. Environmental chemistry analyzed the fate of chemicals in the environment and their adverse effects. This research field developed new concepts and criteria for hazard assessment (Section 4.1). Fourth, from the middle of the 1970 s to the beginning of the 1980 s a regime of regulations of hazardous chemicals evolved. However, this regime continued to regulate chemicals on the basis of empirical evidence about exposure and effects of individual chemicals. Crucial was the distinction between new and existing chemicals because only this distinction facilitated the application of the new regulation [11, phrases 8,9 of Annex 1]. The number of new substances seemed to be manageable and, therefore, it was possible to increase the requirements for risk analysis for this group of substances [11][12]. Therefore, the distinction between new and existing chemicals helped to organize the initial phase of the new regulation. Yet, the success of the new chemicals legislation depended on the quick work up of the burden of the existing chemicals. Eventually, this group of chemicals became the critical factor. After 20 years only some 10 to 100 substances had been comprehensively evaluated, although there are about 30000 commercially important compounds.

\subsection{Towards a Third Generation of Chemicals Policy?}

Similar to the controversial debate in the field of genetic engineering, new legal strategies for solving the problems of 'lack of knowledge' or 'uncertainties of knowledge' were required in the 1990s in the field of chemicals policy. Basic strategies can be arranged into two groups. On the one hand, empirically based strategies take place. Their intention is to provide strategies for policy processes on the basis of experimentally derived knowledge. Relevant is only what is known from empirical evidence. The management of risk has to be based on sound knowledge which will be elaborated by science. The required time span might be long, but, according to this perspective, it will always be possible to generate the knowledge relevant for policy. On the other hand, there is a position which assumes that there will always be a domain of irreducible nonknowledge (to a certain degree, we agree with this perspective). Proponents of this position emphasize precautionary strategies which explicitly take into account the existence and implications of non-knowledge. For example, the European Environment Agency report 'Late lessons from early warnings' [13] states: “Acknowledge and respond to ignorance, as well as uncertainty and risk, in technology appraisal and public policy-making". In particular, the risks of chemicals cannot be described exhaustively. Therefore, it does not make sense to base regulations exclusively on manifest environmental damage or human health effects. In contrast, it is necessary to look for strategies to include different degrees of empirical evidence in a decision. Orientation towards non-knowledge does not mean that no knowledge would be necessary. The point is that, with such a perspective, new strategies of knowledgeproduction have to be developed for scientific research. These strategies do not only aim to generate risk knowledge but also aim to decide whether a specific type of non-knowledge is relevant to risk management or not. In the light of this perspective, we now explore whether there are any fundamental changes in the political debate about REACH. 


\section{REACH: The White Paper and the Current Draft of Legislation}

The EU's concept for a new chemicals legislation was to some extent influenced by the new scientific approaches to hazard assessment developed in the 1990s. Several researchers pointed out the importance of environmental persistence; this focus on persistence as a proxy measure for possible environmental effects made it possible to interpret the precautionary principle in a more stringent way (see Section 4.1.). Influenced by and parallel to this scientific development, there was a political debate in the EU about new concepts for chemicals assessment. This debate was initiated by a report by a Swedish Chemicals Policy Committee published in 1997 [14]; a first summary of this debate is provided by the report 'Chemicals in the European Environment: Low Doses, High Stakes?' published by the European Environment Agency [15]. The changes in the EU methodology for chemicals assessment can be seen as reaction to this debate.

A second important stimulus came from the broader application of the precautionary principle in the environment- and health-related legislation of the EU ([16] for an overview). The precautionary principle achieved the status of a basic principle that is applied when scientific risk assessment is still inconclusive and there are qualified reasons for concern or when violations of a guaranteed level of protection are to be expected $[17$, p. 2]. There are two questions:

i) In which way were issues of uncertainty and non-knowledge addressed in the course of the political debate?

ii) Which political strategies were defined in the new legislation?

We address these questions with respect to two stages in the debate: the publication of the White Paper for a future chemicals policy [2] and the current draft of the REACH legislation [1], see Table 1.

The White Paper refers to the precautionary principle as it was formulated in the general paper on the precautionary principle released earlier [17]. It specifies the precautionary principle for the area of chemicals policy [18]. The White Paper as the basic concept of the new legislation is framed by the following principles [19]:

i) Clear time limits should be defined for the cessation of the discharge of hazardous substances;

ii) Producers should be responsible for providing information about uses and properties of chemicals;

iii) Guidelines facilitating the application of the precautionary principle should be developed;

iv) Chemicals with irreversible toxic effects or PBT properties should be restricted or banned;

Table 1. Comparison of the current EU chemicals legislation with the White Paper of 2001 and the draft of the REACH legislation of June 2006 with respect to key elements of the risk assessment process. RAR: Risk Assessment Reports; PBT: persistent, bioaccumulative, toxic; vPvB: very persistent, very bioaccumulative; PEC: predicted environmental concentration; PNEC: predicted no-effect concentration

\begin{tabular}{lll}
$\begin{array}{l}\text { Industry's re- } \\
\text { sponsibilities }\end{array}$ & $\begin{array}{l}\text { Current legislation } \\
\text { data for new chemi- } \\
\text { cals; participation in } \\
\text { generation of RARs }\end{array}$ & $\begin{array}{l}\text { White Paper } \\
\text { responsible for data } \\
\text { generation and assess- } \\
\text { ments as far as part of } \\
\text { registration; more data if } \\
\text { required }\end{array}$ \\
$\begin{array}{lll}\text { Authorities' } \\
\text { responsibili- } \\
\text { ties }\end{array}$ & $\begin{array}{l}\text { risk assessments for } \\
\text { existing chemicals }\end{array}$ & $\begin{array}{l}\text { evaluation of registra- } \\
\text { tion dossiers (produc- } \\
\text { tion volume }>100 \text { t/a; } \\
\text { substances of concern); } \\
\text { authorization }\end{array}$ \\
\hline 2, p. 6$]$ & &
\end{tabular}

\section{Chemicals}

fundamentally different regimes for new and existing chemicals

all chemicals within one regime; data and testing according to production volume or level of concern

\section{Manufacturing only manufacturers chain and importers ad- dressed $[2$, p. 6$]$}

$\begin{array}{ll}\text { Indicators } & \text { PEC/PNEC (risk); } \\ & \text { PBT, vPvB for marine } \\ & \text { ecosystems (since } \\ \text { 2003) [4] }\end{array}$

downstream users mentioned in addition to manufacturers and importers; broad responsibilities (additional testing and risk assessment; information of authorities/other users)

PBT, vPvB mentioned as properties requiring authorization 2003) [4]

Generation of chemical property data

existing chemicals: targeted towards RARs [2, p. 6]; new chemicals: extent according to production volume (five levels from $10 \mathrm{~kg}$ to $1000 \mathrm{t}$ )

$\begin{array}{ll}\text { Treatment of } & \text { extrapolation factors } \\ \text { uncertainties } & \begin{array}{l}\text { in PNEC derivation; } \\ \text { hazard assessment } \\ \\ \end{array} \\ & \text { (PBT, vPvB) for ma- } \\ & \text { rine ecosystems }\end{array}$
precautionary approach in response to uncertainties about impacts of chemicals

four levels of testing requirements based on production volume (starting at $1 \mathrm{t} / \mathrm{a}$ ); exposure-triggered testing/ waiving

\section{REACH}

responsible for data generation and assessment but with respect to the economic burden [ 1 , phrases 8, 18]

evaluation of registration dossiers (production volume $>100 \mathrm{t} / \mathrm{a}$ substances of concern); authorization

all chemicals within one regime; polymers excluded; phase-in substances [1, p. 47f.] with special registration regime and transitional provisions [1, p. 83f.]

downstream users mentioned in addition to manufacturers and importers

$\mathrm{PEC/PNEC}$ as part of chemical safety assessment (substances $>10$ t/a)

PBT part of hazard assessment (included in chemical safety assessment; for substances $>10 \mathrm{t} / \mathrm{a})$

four levels of testing requirements based on production volume (starting at $1 \mathrm{t} / \mathrm{a}$ ); exposure-triggered testing/ waiving; but data not sufficient in some cases (section 4)

generalization of hazard assessment with respect to PBT- and vPvB-substances; but exceptions (see section 4.4) v) The costs of risk assessment should be shifted from the general public to industry.

Essential elements of the White Paper were the requirement for registration for all substances with a production volume exceeding $1 \mathrm{t} / \mathrm{a}$ in a coherent system, the development of a scale to differentiate between different degrees of concern and of a corresponding tiered strategy of risk management; exchange of information along the supply chain and increased responsibility of downstream users, authorization of substances of very high concern; and the substitution of hazardous chemicals (pages $7,12,17$, and 8 of the White Paper) [2] (see Table 1). The White Paper aims at a consistent framework that focuses administrative 
resources on the regulation of compounds 'of very high concern'. Moreover, a system should be established which helps to identify problematic compounds not yet known. Well-defined indicators of hazard and risk and criteria differentiating between high and low hazard or risk are essential for such a regime to work $[20$, p. 111,133$]$.

After publication of the White Paper the political debate focused rapidly on the economic costs of REACH. If the principle of 'no data - no market' was to be implemented, large amounts of data had to be generated. Costs estimates range from a total of 2.1 billion $€$ (White Paper) to 10 billion $€$ (European Chemical Industry Council, CEFIC) $[19$, p. 73]. Some studies estimated workplace losses to be around 1 million (Arthur D. Little; [19, p. 73]). Economic aspects began to dominate the perception of REACH and to some extent the actors lost sight of the political goal of a chemicals policy oriented towards the precautionary principle $[10$, p. 5]. However, the general line of policy was still oriented towards the precautionary principle [1, phrase 9, p. 4] and the differences between the White Paper and the final version of REACH are not in the general principles but in the details of the new legislation (Table 1 and Section 4).

Several important innovations of the chemicals policy were transferred from the White Paper to the current draft of REACH:

i) Division of work between industry and authorities with high responsibility of industry;

ii) The manufacturing chain from producers to downstream users of chemicals is involved in the generation of knowledge about chemical properties, uses, and risks;

iii) The emphasis on PBT and vPvP indicators constitutes a new framework of precaution; thereby, the problems of limited knowledge are acknowledged at the conceptual level of the legislation;

iv) By the category of 'phase-in' substances the old regulatory regime is transferred into a new one which is expected to solve the problem of the existing chemicals;

v) An European Chemicals Agency will be established. One important mission of the agency is to collect and distribute knowledge about hazardous chemicals. The agency will serve as platform to provide data for the general public [1, Article 118].

The touchstone of the new chemicals regulation is at the level of specific indicators and criteria. The limits of the application of the precautionary principle as foreseen under REACH can be shown by three aspects: i) Data requirements under $\mathrm{REACH}$ are not sufficient to quantify the hazard indicators. In the White Paper, PBT chemicals are treated similar to CMR chemicals (carcinogenic, mutagenic, toxic to reproduction) but for the generation of data there are no details listed. In the current draft, however, the data requirements for chemicals below $100 \mathrm{t} / \mathrm{a}$ are not sufficient for the PBT assessment that is required for these chemicals. One example is the longterm toxicity test with daphnia that was required under certain circumstances at the level of $1 \mathrm{t} / \mathrm{a}$ in an earlier draft of the legislation [21, Annex V, $7.1]$; in the current draft, this test is not required at this tonnage level. Another example is the availability of environmental half-lives for the $\mathrm{P}$ assessment, see Section 4.3.

ii) There is no political debate about a set of optimal hazard indicators. Instead, the debate has been dominated by the question of which tests are required at which tonnage level. This turn towards practical questions of data requirements and costs is, however, not only caused by the priority of economic aspects. It is also caused by a lack of fully developed scientific concepts of hazard assessment.

iii) Finally, there is the problem of phasein substances, which will replace the current category of existing chemicals. High-production volume chemicals and CMR chemicals will have to be registered first (three years after entry into force of REACH); for lower tonnage levels, registration is only required within 6 or 11 years after entry into force of REACH, see de Avila and Sandberg [22]. Without doubt, the problem of the existing chemicals cannot be solved without a transition period. However, with respect to the precautionary principle it will be crucial that there are no delays. Ultimately, the practical application of the system will demonstrate how effective the proposed solution is.

In conclusion, the precautionary principle has been implemented by the White Paper as a guiding principle. Important aspects of the final legislation will most likely be based on the precautionary principle as well. However, the set of hazard indicators to be used under REACH was not based on a systematic concept of proxy measures indicating possible risk. Moreover, insufficient data requirements will hamper the application of the hazard indicators included in the legislation. To put it in a picture: in the course of implementing the precautionary principle in the field of chemicals policy it seems that the roof was built before the foundations. In the following section, we analyze in more detail the problem of insufficient data for PBT assessments under REACH.

\section{Dealing with Uncertainty and Lack of Knowledge: Hazard Assessment}

\subsection{Development of Exposure- based Hazard Indicators in the 1990s}

Persistence, bioaccumulation and toxicity were identified as key dimensions of unwanted inherent properties of chemicals in the 1970s and early 1980 s (inherent: independent of the amounts released). Soon after chemicals legislations had been established in many industrialized countries, methods for selecting priority chemicals of concern were developed [23]. The overall concept of these methods was called 'hazard assessment', the term hazard initially including all aspects of release rate, exposure/ environmental fate, and toxic effects. In the early 1990 s, the three dimensions of $\mathrm{P}, \mathrm{B}$ and $\mathrm{T}$ were combined in methods that were designed to explicitly address these three properties, e.g. under the OSPAR Convention or in the Waste Minimization National Plan of the US [24]. Thereby, chemicals of particular concern were identified in terms of these three inherent properties.

In the 1990s, methods for the risk assessments of new and existing chemicals were developed in the EU and described in the Technical Guidance Document (TGD) of 1996 [3]. According to the TGD, the quotient of a chemical's predicted environmental concentration (PEC) and predicted no-effect concentration (PNEC) has to be determined for several environmental compartments. The PEC reflects the amounts of a chemical actually released to the environment and the chemical's environmental fate (partitioning, degradation, transport); the PNEC is derived from toxicity data by application of extrapolation factors depending on the type of toxicity test, the number of data points etc. With the establishment of the risk assessment methods described in the TGD, hazard and risk can be distinguished more clearly [25]. Risk indicates to what extent toxic effects are possible and is expressed in terms of the risk quotient, PEC/PNEC; estimates of risk are based on actual emissions. Hazard now refers to inherent properties of a chemical that are independent of the amount and pattern of release, such as persistence, bioaccumulation potential, and toxicity; hazard indicates a potential for certain effects.

Also in the $1990 \mathrm{~s}$, several scientific studies emphasized the importance of the $\mathrm{P}$ dimension. Klöpffer and also Scheringer and Berg pointed out that a chemical's persistence and spatial range or travel distance 
indicate a potential for unwanted environmental exposure and that chemicals with high persistence and spatial range should not be released to the environment even if their toxicity has not yet been determined [26]. Scheringer [27], Bennett et al. [28], Hertwich and McKone [29], and Beyer et al. [30] presented multimedia fate models that can be used to estimate overall persistence $\left(P_{\mathrm{ov}}\right)$ and long-range transport potential (LRTP) of organic chemicals. An overview of these approaches can be found in Scheringer et al. [25].

Conceptually, these studies are important because they demonstrate the feasibility of an 'exposure-based hazard assessment': persistence and LRTP are hazard indicators reflecting the potential for long-term and large-scale exposure. Their relevance derives from the precautionary principle: persistence and transport distance indicate whether environmental impacts of a chemical, if they occur, would last long times and cover large areas. Persistence and LRTP can be determined even if toxicity data are not available and their calculation requires less data and time than a full hazard assessment (exposure and effects), let alone a full risk assessment. Calculation of persistence and LRTP with simple multimedia models is a hazard screening step that can be performed at the beginning of a hazard and risk assessment of a chemical. Fenner et al. [31] have compared nine models available for $P_{\mathrm{ov}}$ and LRTP calculations; on this basis, an OECD expert group has developed a consensus model for $P_{\mathrm{ov}}$ and LRTP screening that is provided by the OECD [32].

Parallel to the development of methods for $P_{\text {ov }}$ and LRTP assessment, a shift from risk assessment to hazard assessment and from effect-based indicators to exposure-based indicators was proposed and the precautionary principle was invoked as an argument for this shift. In 1999, in the journal, Human and Ecological Risk Assessment, the question "Does the precautionary principle have a role in ecological risk assessment?" was put up for discussion. Several authors controversially discussed the role of risk and hazard assessment and different interpretations of the precautionary principle [33]. This scientific and political discussion in the second half of the 1990s science and politics are closely linked here - significantly influenced the preparation of the White Paper published in 2001.

\subsection{Hazard-based Indicators in EU documents}

A PBT assessment was not mentioned in the first edition of the TGD of 1996. In section 4.5 of part II of the TGD of 1996 , there is a short discussion of cases in which a PEC or PNEC cannot be calculated but no reference to a PBT assessment as a possible alternative is made. In the revised TGD of
2003, the PBT assessment is included; in chapter 4.4 , it is described how $\mathrm{P}, \mathrm{B}$ and $\mathrm{T}$ should be evaluated as part of the risk assessment for marine ecosystems. This procedure is proposed in the TGD because PEC and/or PNEC cannot be determined with sufficient reliability for marine ecosystems. Since it is intended to protect marine ecosystems from chemicals with unwanted hazard properties, a PBT assessment is considered appropriate in this case.

Even before the second edition of the TGD was published in 2003, the White Paper on the Strategy for a Future Chemicals Policy was presented in February 2001. In the White Paper, PBT chemicals and vPvB chemicals are mentioned explicitly; like CMR chemicals, they are defined as a group of chemicals that should only be put on the market after authorization. Therefore, the White Paper represents an important conceptual change. In the scientific studies and political discussions mentioned in Section 4.1, the functioning of the risk assessment procedure was questioned. In reaction to this, a higher emphasis has been given to hazard assessment in the EU methodology. In a first step (TGD of 2003), the risk assessment procedure was replaced by a hazard assessment for a case with very high uncertainties and high vulnerability (marine ecosystems). In a second step (White Paper), hazard-based indicators are proposed to define categories of chemicals of very high concern in analogy to the category of CMR chemicals (authorization of PBT and vPvB chemicals). According to the White Paper, these chemicals should be subject to authorization regardless of the outcome of a risk assessment and of the measures taken to control the risk. In REACH [1], finally, for every chemical produced or im- ported in amounts exceeding $10 \mathrm{t} / \mathrm{a}$, a PBT assessment is required as part of the chemical safety assessment (chemicals between 1 and 10 t/a have to be screened for PBT properties by means of QSAR estimates, as defined in Annex III of REACH). However, for chemicals produced in less than $100 \mathrm{t} / \mathrm{a}$ (about 20,000 chemicals), the available data are not sufficient to actually performing the PBT assessment (this inconsistency is addressed in Section 4.3. below). For chemicals meeting the PBT criteria, the registrant is required to perform an emission characterization as part of the chemical safety assessment (REACH, Annex I, p. 16). This chemical safety assessment will be used by the authorities as basis for evaluation and, to some extent, for authorization.

\subsection{Application of PBT Indicators under REACH}

Annexes VII to X of REACH define the data requirements for the different tonnage levels. In Table 2, the PBT-related data required for the three tonnage levels from 1 to 10,10 to 100 , and 100 to $1000 \mathrm{t} / \mathrm{a}$ are listed along with the PBT criteria defined in Annex XIII of REACH.

Comparison of the required data with the criteria shows that only at $100 \mathrm{t} / \mathrm{a}$ the chemical properties provided are sufficient for a PBT assessment. For chemicals in the lower tonnage ranges, the data for all three dimension, $\mathrm{P}, \mathrm{B}$ and $\mathrm{T}$, are not sufficient. Hence, estimation procedures will be required to identify possible PBT chemicals. What are possible ways to deal with this problem of insufficient data?

For the $\mathrm{B}$ dimension, relationships between BCF and $K_{\mathrm{ow}}$ will have to be used [34]. For the T dimension, long-term NOECs will have to be estimated from short-term

Table 2. Increasing data requirements and evaluation criteria for PBT assessment under REACH. $K_{\mathrm{ow}}$ : octanol-water partition coefficient; BCF: bioconcentration factor; NOEC: no-observed effect concentration; CMR: carcinogenic, mutagenic, or toxic to reproduction. Data requirements for higher tonnage levels are in addition to those for lower tonnage levels. Compare also de Avila and Sandberg [22].

\begin{tabular}{|c|c|}
\hline & $\mathbf{P}$ \\
\hline $\begin{array}{l}1-10 \text { t/a (but only for } \\
\text { chemicals specified in } \\
\text { Annex III): Annex VII }\end{array}$ & $\begin{array}{l}\text { test for ready biode- } \\
\text { gradability }\end{array}$ \\
\hline
\end{tabular}

Annex III): Annex VII

10-100 t/a: hydrolysis

Annex VII and VIII

100-1000 t/a: Annex VII, VIII and IX

PBT criteria from Annex XIII

\section{B \\ ow}

$-$

simulation tests for ultimate biodegradation in water (also soil, sediment)

measured half-lives in freshwater (40 d), seawater $(60 \mathrm{~d})$, soil (120 d) or sediment (180 d, marine; $120 \mathrm{~d}$, freshwater)

\section{measured BCF, fish long-term test} daphnia and fish

BCF measured for aquatic species greater than 2000

long-term NOEC below $0.01 \mathrm{mg} / \mathrm{l}$ or CMR or other
$\mathbf{T}$

short-term test, daphnia (long-term test possible but not required)

short-term test, fish (long-term possible) evidence 
data [35]. For the $\mathrm{P}$ assessment, half-lives have to be derived from chemical structure or from results from 'ready biodegradability' tests. In this section, we discuss this part of the data problem in more detail.

Half-life estimation methods are available but still yield highly uncertain results for numerical half-life values [36]. The BIOWIN estimation software, which is part of the EPI (Estimation Program Interface) Suite provided by the US EPA [37], derives measures of biodegradability from chemical structure. Aronson et al. [36] evaluated the performance of BIOWIN in predicting environmental half-lives and Fenner et al. [36] found a mean-squared error of about a factor of 5 in their estimated relationship between half-lives and BIOWIN model output.

If the half-lives are uncertain by a factor of 5, we can calculate $x$ as the half-life threshold of REACH divided by 5 and $y$ as the half-life threshold multiplied by 5 . For water with a half-life criterion of 40 days, these values are $8(x)$ and 200 days (y). Then, all chemicals with estimated half-lives of $x$ or greater are possible $\mathbf{P}$ chemicals although their (estimated) halflives are below the threshold (possible false negatives). Conversely, all chemicals with estimated half-lives of $y$ or lower might be no $\mathrm{P}$ chemicals although their (estimated) half-life exceeds the threshold (possible false positives).

Compilations of environmental halflives show that half-life values are log-normally distributed. A data set with soil and water half-lives for about 400 chemicals based on data from Aronson et al., Arnot et al. and Fenner et al. [36] leads to a log-normal distribution with a median of 38 days and a factor of 100 between 10 th and 90 th percentile (Fig. 1).

If we assume that the set of approximately 30000 chemicals to be registered under REACH exhibits a similar log-normal distribution of half-lives as observed in the set of 400 chemicals, approximately 9000 chemicals $(30 \%)$ have half-lives between 8 and 40 days (possible false negatives) and also $9000(30 \%)$ half-lives lie between 40 and 200 days (possible false positives). The number of half-lives exceeding 200 days (half-life threshold multiplied by 5), i.e. the number of $\mathrm{P}$ chemicals, is about 5700 chemicals $(19 \%)$. (With the soil half-life threshold of 120 days, the picture is similar: $x$ is equal to 25 days, $y$ is 600 days, and there are $10000(33 \%)$ possible false negatives, $6000(20 \%)$ possible false positives, and 2000 chemicals $(7 \%)$ with half-lives greater than 600 days $(y))$.

In other words, we should expect at least 2000 persistent chemicals, and the number of possibly persistent chemicals that might not be detected is substantial: it is given by the fraction of false negatives among the

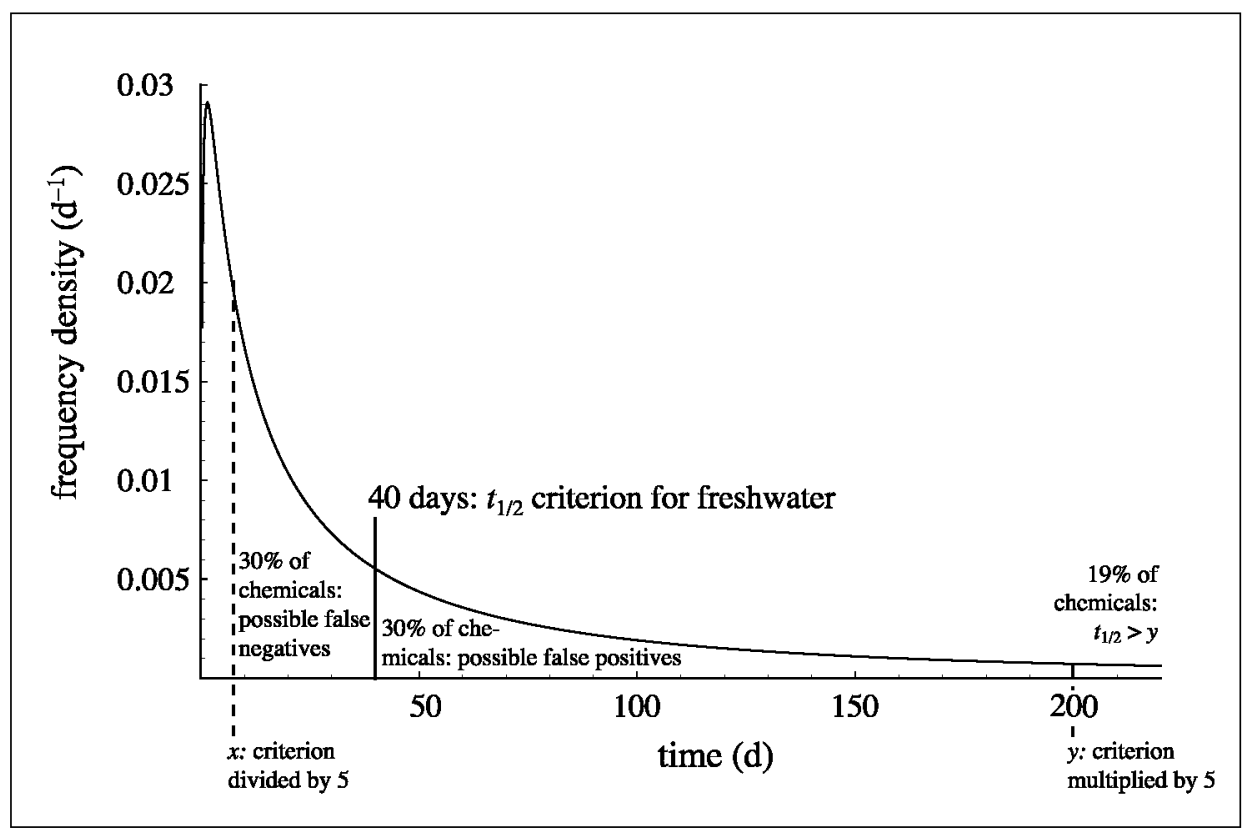

Fig. 1. Log normal distribution of half-lives with a median of 38 days and a factor of 100 between 90 th and 10th percentile. The solid line indicates the half-life criterion for water, dashed lines indicate the range of estimated half-lives including the criterion of $40 \mathrm{~d}$ if the mean error of half-life estimates is a factor of 5 .

10,000 chemicals with half-lives between $x$ and the threshold. This fraction is largely unknown but might include several 100 or even several 1000 chemicals. The fact that there might be several 1000 chemicals for which it is possible that their $\mathrm{P}$ character is not detected because of uncertain half-life estimates is a source of concern. What can be done to replace this concern by sound information?

The above estimates are rough but based on the (limited) empirical evidence that is currently available. To replace these rough estimates with more substantial numbers, a joint effort of industry, science, and governments to measure a large number of half-lives under environmentally relevant conditions is needed. More and more reliable half-life data will be helpful in several respects: First, on the basis of more experimental data, half-life estimation methods can be improved so that estimated values for chemicals for which still no measured values are available might be less uncertain than at present. Fenner et al. [36] conclude from their analysis of half-life estimation methods: "In the future, models that allow for a more accurate prediction of half-lives will only be obtained through training on actually measured half-lives. In doing so, the challenge lies in separating the influence of molecular structure on biochemical reactivity from the confounding influences of different environmental and experimental conditions under which biodegradation rates have been measured." Second, improved estimation methods will reduce the number of possible false negatives and possible false positives, which is desirable from an ecological and economical point of view.
Third, more experimental half-life data will lead to better estimates of the overall distribution of half-lives so that estimates of how many chemicals lie in which half-life range can be improved.

\subsection{Conclusions on Use of PBT Assessments under REACH}

PBT assessments have been introduced under REACH to reduce, for chemicals of very high concern, the influence of uncertainties associated with a full risk assessment. With reference to the precautionary principle, the assessment of certain substances of very high concern (PBT, vPvB) will be based on inherent properties. What are the main uncertainties that are still associated with the treatment of possible PBT chemicals under REACH?

For chemicals below $100 \mathrm{t} / \mathrm{a}$, the data required by the PBT criteria in Table 2, bottom are not generally available and will have to be estimated. An important question is here whether estimated data will be sufficient as a basis to include chemicals with PBT properties in Annex XIV of REACH, see Heiß et al. [38]. Annex XIV contains the list of chemicals which can only be used upon authorization. The authorities have to demonstrate that a chemical meets criteria for substances of very high concern and should therefore be included in Annex XIV. A possible scenario is that authorities when they evaluate possible substances of very high concern, ask for measured PBTrelated data as listed in Table 2. If this is not possible, the limited and uncertain data basis for chemicals below 100 t/a would be a major obstacle to an effective identification and assessment of PBT chemicals as it 
was initially intended with the introduction of REACH.

However, this treatment of possible PBT chemicals (inclusion in Annex XIV and authorization) will probably only become effective for chemicals for which the registrant has not been able to demonstrate 'adequate control' of risks in the chemical safety assessment. Adequate control for PBT and $\mathrm{vPvB}$ chemicals means that emissions are not relevant (section 4 of Annex I). Yet, criteria for 'relevant' emissions still need to be defined. The purpose of the above approach is to focus resources of the authorities on the evaluation of substances for which significant exposure might occur. However, this approach also implies that it is possible to exclude possible PBT chemicals from the authorization procedure on the basis of an estimation of emissions. This, in turn, means that decisions about possible PBT chemicals in the first instance have to deal with some of the typical uncertainties of a risk assessment (emissions, exposure pathways), even if a chemical meets the PBT criteria of Annex XIII. In this situation, authorities could, in the course of the evaluation procedure, demonstrate that adequate control is not given and the hazardbased evaluation of a possible PBT chemicals would become relevant again. This will, however, be possible only in a limited number of cases.

In conclusion, the replacement of a risk assessment by a hazard assessment, as it was initially intended in the White Paper for PBT chemicals, is not implied by the PBT properties of a chemical but will have to be based on case-specific arguments for every individual chemical.

\section{Outlook: Chemicals Policy as Politics of Non-knowledge?}

In the development of REACH, science and politics have mutually influenced each other but with different directions of the influence in different phases of the process. First, methods of hazard assessment were developed in environmental research and were controversially discussed amongst scientists. Next, these methods and concepts were picked up by political actors who wanted to argue for a more stringent interpretation of the precautionary principle. Then the scientists, in turn, were expected to develop additional and more consistent and ready-to-use hazard assessment methods. Our interpretation is that policy was more rapid in the implementation of scientific concepts of hazard assessment than research was able to further develop these concepts. This might have contributed to the definition of insufficient data requirements for the $\mathrm{PBT}$ assessment under REACH. In other words, from a certain point in time on, the political process was not supported sufficiently by the scientific development of methods for hazard assessment. It is somewhat ironic that the earlier concepts of hazard assessment were transferred so quickly into the political system that the further concretion of the concepts fell behind. Nevertheless, the current situation should be taken as a challenge, not only to further develop the methods and concepts of hazard assessment, but also to reflect and shape the relationship between science and politics and to address the problem of missing knowledge in chemicals assessment. Some of these challenges are briefly outlined in the following.

There are two answers to the question in the title of our article "Will we know more or less about chemical risks under REACH?" On the one hand, under REACH we will certainly know more about chemical risks, because the generation of data will be required and the management of knowledge and information will be improved. On the other hand, we will know less than what could have been possible, namely with respect to our knowledge about nonknowledge. What can be done to improve the methods of hazard assessment, not only to develop indicators pointing out possible risks in a plausible way and supporting the application of the precautionary principle, but also to make them applicable for users in industry and authorities? We suppose that it will be necessary to reflect on the basic principles of hazard assessment research. The following needs can be stated:

i) Establishment of a new practice in dealing with non-knowledge. Nonknowledge is not primarily 'specified ignorance' that can be converted into knowledge in the course of further research [39]. Instead, the domain of non-knowledge also contains fundamental non-knowledge. It is a task for future concepts of hazard assessment to explore the boundaries between specified ignorance and fundamental non-knowledge. In addition, hazard assessment should help to communicate the different forms of non-knowledge.

ii) With respect to responsibility for impacts on environmental and human health and liability, the required degree of empirical evidence is a crucial point. What types of scientific proof are possible in the field of chemical risk assessment? More generally, the development of a new culture of evidence is required that helps to evaluate and use facts of different degree of reliability.

iii) Another important aspect is the practice inherent to the scientific method ([40] for an overview). Which scientific approach makes it possible to construct a "network of indications of possible risk'? What data are needed to determine hazard and risk indicators and to what extent will data derived from the molecular structure (instead of measured data) be available and acceptable? What are most intelligent and efficient testing strategies?

iv) Finally, requirements of political actors should be integrated in the development of hazard indicators. These indicators should not only be constructed in a scientifically convincing way, but also reflect the needs of political decision making processes.

In addition to the scientific challenges, there are also political tasks. A key question is to what extent it is possible to improve the institutional and political boundary conditions for a more stringent interpretation and application of the precautionary principle. This would have important implications. First, a further change of the regulatory regime could have the side-effect of closing innovative pathways. Substances that are eliminated on the basis of a precautionary approach could bear the potential for important innovations. However, regulations on the basis of a precautionary approach also stimulate research into new classes of substances that combine a low hazard profile and a high technical performance [41]. Second, even a change towards a precautionary approach of regulation will not guarantee complete safety. It is conceivable that also substances in agreement with the criteria of a precautionary regulation regime could turn out to be risky innovations. Nevertheless, it is possible and desirable to improve the processes of societal learning by including not only scientific knowledge but also non-knowledge in decision making processes.

\section{Acknowledgement}

We thank Christoph Schulte, Burkhard Wagner, Kathrin Fenner, Christine Heiß, and Matthew MacLeod for helpful comments.

Received: August 14, 2006

[1] Council of the European Union, Common position adopted by the Council (REACH); (7524/06) Luxembourg, 2006, http://register:consilium.europa.eu/pdf/ en/06/st07/st07524.en06.pdf.

[2] EU (Commission of the European Communities), 'White paper for a Future Chemicals Policy, Com (2001) 88 final', European Commission, Brussels, 2001.

[3] Technical Guidance Document in Support of Commission Directive 93/67/EEC on Risk Assessment for New Notified Substances and Commission Regulation (EC) No. 1488/94 on Risk Assessment for Existing Substances. Office for Official Publications of the European Communities, Luxembourg, 1996. 
[4] Technical Guidance Document on Risk Assessment in Support of Commission Directive 93/67/EEC on Risk Assessment for New Notified Substances, Commission Regulation (EC) No. 1488/94 on Risk Assessment for Existing Substances, Directive 98/8/EC of the European Parliament and the Council concerning the Placing of Biocidal Products on the Market, Joint Research Institute, Ispra, 2003.

[5] S. Böschen, in 'Entsetzliche soziale Prozesse. Theorie und Empirie der Katastrophen', Ed. L. Claussen, E. Geenen, E. Macamo, Lit, Münster, 2003, p. 139; S. Böschen, in 'Wenn der Geist die Materie küßt', Ed. K. Griesar, Harri Deutsch, Frankfurt am Main, 2004, p. 179.

[6] P. Levi, 'The Periodic Table', Michael Joseph, London, 1985.

[7] F.J. Brüggemeier, 'Das unendliche Meer der Lüfte. Luftverschmutzung, Industrialisierung und Risikodebatten im 19. Jahrhundert', Klartext, Essen, 1996; F. Ewald, 'Der Vorsorgestaat', Suhrkamp, Frankfurt am Main, 1993.

[8] J. Radkau, 'Natur und Macht. Eine Weltgeschichte der Umwelt', Beck, München, 2000.

[9] J.K. Nichols, P.J. Crawford, 'Managing Chemicals in the 1980s', OECD, Paris, 1982; K. Christiansen, B. Koch, F. BroRasmussen, 'Chemicals in the Environment - Chemicals Testing and Hazard Ranking - The Interaction between Science and Administration', The Technical University of Denmark, Lyngby, 1983; R. Lönngren, 'International Approaches to Chemicals Control - A Historical Overview', The National Chemical Inspectorate, Stockholm, 1992

[10] S. Løkke, Envinn. Sci. Pollut. Res. 2006, 13, dx.doi.org/10.1065/espr2006.06.31.

[11] OECD (Organisation for Economic Cooperation and Development), 'OECD Guidelines in respect of Procedures and Requirements for anticipating the Effects of Chemicals on Man and in the Environment', OECD, Paris, 1977, phrases 8, 9 of Annex 1.

[12] 'OECD and the Environment', OECD, Paris, 1979.

[13] EEA, 'Late lessons from early warnings: the precautionary principle 1896-2000', Environmental issue report, No 22. European Environment Agency, Copenhagen, 2001, p. 168.

[14] Swedish Ministry of the Environment, 'Towards a Sustainable Chemicals Policy', English Summary, Chemicals Committee, Stockholm, 1997; ENDS (Environmental Data Services) Report, 1997, 269, 21.

[15] EEA, 'Chemicals in the European Environment: Low Doses, High Stakes?', European Environment Agency, Copenhagen, 1998.

[16] I. Appel, 'Staatliche Zukunfts- und Entwicklungsvorsorge', Mohr Siebeck, Tübingen, 2005.
[17] EU (Commission of the European Communities), 'Communication from the Commission on the precautionary principle. Com (2000) 1 final', European Union, Brussels, 2000.

[18] EU (Commission of the European Communities), 'White paper for a Future Chemicals Policy. Com (2001) 88 final', European Commission, Brussels, 2001, p. 5; I. Appel, in 'Das Europäische Weißbuch zur Chemikalienpolitik', Ed. R. von Hendler, P. Marburger, M. Reinhardt, M. Schröder, Erich Schmidt, Berlin, 2003, p. 105.

[19] K. Jacob, A. Volkery, 'Technikfolgenabschätzung - Theorie und Praxis', 2005, 14, 69 .

[20] I. Appel, in 'Das Europäische Weißbuch zur Chemikalienpolitik', Ed. R. von Hendler, P. Marburger, M. Reinhardt, M. Schröder, Erich Schmidt, Berlin, 2003.

[21] EU (Kommission der Europäischen Gemeinschaften), Vorschlag für eine Verordnung des Europäischen Parlaments und des Rates zur Registrierung, Bewertung, Zulassung und Beschränkung chemischer Stoffe (REACH), zur Schaffung einer Europäischen Agentur für chemische Stoffe sowie zur Änderung der Richtlinie 1999/45/EG und der Verordnung (EG) über persistente organische Schadstoffe und Vorschlag für eine Richtlinie der Europäischen Parlamentes und des Rates zur Änderung der Richtlinie 67/548/EWG des Rates und ihrer Anpassung an die „REACH-Verordnung“, 2003.

[22] C. de Avila, E. Sandberg, Chimia, 2006, 60,645 .

[23] F. Korte, W. Klein, B. Drefahl, Naturwissenschaftliche Rundschau 1970, 23, 445; F. Schmidt-Bleek, W. Haberland, A.W. Klein, S. Caroli, Chemosphere 1982, 11, 383; D. Freitag, H. Geyer, A. Kraus, R. Viswanathan, D. Kotzias, A. Attar, W. Klein, F. Korte, Ecotox. Environ. Safety 1982, 6, $60 ;$ R. Frische, G. Esser, W. Schönborn, W. Klöpffer, Ecotox. Environ. Safety 1982, 6, 283.

[24] OSPAR Convention for the protection of the marine environment of the North-East Atlantic. www.ospar.org/eng/html/welcome.html, Oslo Paris (OSPAR) Commission, Paris 1992; US EPA, Waste minimization national plan, 1996, www.p2pays. org/ref/36/35486.pdf.

[25] M. Scheringer, M. Matthies, K. Hungerbühler, Environ. Sci. Pollut. Res. 2001, 8, 150.

[26] W. Klöpffer, Environ. Sci. Pollut. Res. 1994, 1, 108; M. Scheringer, M. Berg, Fresen. Environ. Bull. 1994, 3, 493.

[27] M. Scheringer, Environ. Sci. Technol. 1996, 30, 1652.; M. Scheringer, Environ. Sci. Technol. 1997, 31, 2891.

[28] D.H. Bennett, T.E. McKone, M. Matthies, W.E. Kastenberg, Environ. Sci. Technol. 1998, 32, 4023; D.H. Bennett, W.E. Kastenberg, T.E. McKone, Environ. Sci. Technol. 1999, 33, 503 .
[29] E.G. Hertwich, T.E. McKone, Environ. Sci. Technol. 2001, 35, 142.

[30] A. Beyer, D. Mackay, M. Matthies, F. Wania, E. Webster, Environ. Sci. Technol. 2000, 34, 699

[31] K. Fenner, M. Scheringer, M. MacLeod, M. Matthies, T.E. McKone, M. Stroebe, A Beyer, M. Bonnell, A.C. Le Gall, J. Klasmeier, D. Mackay, D. van de Meent, D.W. Pennington, B. Scharenberg, F. Wania, Environ. Sci. Technol. 2005, 39, 1932.

[32] F. Wegmann, L. Cavin, M. MacLeod, M. Scheringer, K. Hungerbühler, in preparation for Environ. Mod. Software, 2007.

[33] D. Santillo, P. Johnston, Human Ecological Risk Assessment 1999, 5, 923; C.A. Pittinger, W.E., Bishop, Human Ecological Risk Assessment 1999, 5, 951.

[34] F.A.P.C. Gobas, H.A. Morrison, in 'Handbook of Property Estimation Methods for Chemicals', Ed. D. Mackay, Lewis Publishers, Boca Raton, 2000.

[35] R. Länge, T.H. Hutchinson, N. Scholz, J. Solbé, Chemosphere 1998, 36, 115.

[36] J. Arnot, T. Gouin, D. Mackay, 'Practical Methods for Estimating Environmental Degradation Rates', Canadian Environmental Modelling Network, 2005; D. Aronson, R. Boethling, P. Howard, W. Stiteler, Chemosphere 2006, 63, 1953; K. Fenner, S. Canonica, B.I. Escher, L. Gasser, S. Spycher, H.C. Tülp, Chimia 2006, $60,683$.

[37] US EPA, EPI Suite 3.12. Available from the US EPA Office of Pollution Prevention and Toxics, www.epa.gov/oppt/exposure/ docs/episuite.html, 2004

[38] C. Heiß, C. Hoffmann, C. Schulte, L. Tietjen, U. Frank, Chimia 2006, 60, 661.

[39] R.K. Merton, Ann. Rev. Sociol. 1987, 13, 1.

[40] K. Knorr-Cetina, 'Epistemic Cultures: How sciences make knowledge', Havard University Press, Cambridge, MA, 1999; H.J. Rheinberger, 'Experimentalsysteme und epistemische Dinge. Eine Geschichte der Proteinsynthese im Reagenzglas', Wallstein, Göttingen, 2001.

[41] P.-G. Rieger, H.-M. Meier, M. Gerle, U. Vogt, T. Groth, H.-J. Knackmuss, J. Biotechnol. 2001, 94, 101. 